\title{
DESAFIOS E OPORTUNIDADES: COMO A PROJEÇÃO DE PODER CHINESA SE ADAPTA AO NOVO NORMAL
}

Ana Carolina Cordeiro ${ }^{1}$ Demian Castro

Resumo: Déficit de financiamento, urgência na reestruturação da economia interna, motins em Hong Kong, Guerra Comercial e conflitos na área de tecnologia avançada, obstáculos para continuidade de projetos referentes à iniciativa de política externa Belt and Road Initiative (BRI): o panorama de crise pela pandemia do novo coronavírus impacta a China de diferentes formas e é potencializado pela relação conflituosa com os Estados Unidos. Ainda assim, novas oportunidades surgem em meio às adversidades e a construção do mundo pós-pandemia conta ativamente com a participação da China de Xi Jinping, que mantém o foco em cooperação internacional e em desenvolvimento tecnológico.

Palavras-chave: China. Belt and Road Initiative. Pandemia covid-19.

\section{CHALLENGES AND OPPORTUNITIES: HOW CHINESE POWER PROJECTION ADAPTS TO THE NEW NORMAL}

Abstract: Financing deficit, urgency in the restructuring of the domestic economy, riots in Hong Kong, trade war and conflicts in the area of advanced technology, obstacles to the continuity of projects related to the foreign policy Belt and Road Initiative (BRI): the panorama of crisis due to the new coronavirus pandemic impacts China in different ways and is enhanced by the conflicting relationship with the United States. Even so, new opportunities arise in the midst of adversities and the construction of the post-pandemic world actively counts on the participation of China under Xi Jinping administration, who keeps the focus on international cooperation and technological development.

Keywords: China. Belt and Road Initiative. Pandemic covid-19.

\section{RETOS Y OPORTUNIDADES: CÓMO SE ADAPTA LA PROYECCIÓN DE PODER CHINESA A LA NUEVA NORMALIDAD}

Resumen: Déficit de financiamiento, urgencia en la reestructuración de la economía nacional, disturbios en Hong Kong, guerra comercial y conflictos en el área de tecnología avanzada, obstáculos a la continuidad de proyectos relacionados a la iniciativa de política exterior Belt and Road Initiative (BRI): el panorama de la pandemia afecta a China de diferentes maneras y se ve reforzada por la relación conflictiva con los Estados Unidos. Aun así, surgen nuevas oportunidades en medio de la adversidad y la construcción del mundo pos-pandémico cuenta activamente con la participación de China de Xi Jinping, que mantiene el foco en la cooperación internacional y en el desenvolvimiento de tecnológia.

Palabras clave: China. Belt and Road Initiative. Pandemia covid-19.

\footnotetext{
${ }^{1}$ Universidade Federal do Paraná, Departamento de Ciências Econômicas e Programa de PósGraduação em Políticas Públicas, Curitiba, Brasil, carolina.cordeiro7@gmail.com, https://orcid.org/0000-0001-9093-4277

2 Universidade Federal do Paraná, Departamento de Ciências Econômicas e Programa de PósGraduação em Políticas Públicas, Curitiba, Brasil, demian@ufpr.br, https://orcid.org/0000-0002-18250097
} 


\section{Introdução}

A iniciativa chinesa Belt and Road visa construir, juntamente com outros países, rotas terrestres marítimas conectando diferentes continentes, com o objetivo de estabelecer zonas de livre comércio, facilitar a importação e exportação de produtos e expandir as áreas de comércio e tecnologia (NDRC, 2015). O projeto de Xi Jinping precisará superar uma infinidade de dificuldades para a sua implementação. Além de questões nacionais internas, o contexto pandêmico pela covid-19 trazido no ano de 2020 impôs mais desafios à Política Externa Chinesa. Como resultado, o trabalho em alguns projetos foi interrompido, alguns foram descartados e muitos dos empréstimos estão sendo renegociados, à medida que os países devedores - atingidos pela covid-19 procuram adiar os pagamentos à China (ECONOMIST, 2020). Além disso, 40\% dos projetos BRI foram atrasados e outros $20 \%$ foram gravemente afetados pela covid-19. (GOULARD 2020).

A pandemia, no entanto, não se trata do único desafio significativo para Pequim. A aplicação da Lei de Segurança em Hong Kong é vista de maneira negativa por países do ocidente, e a expansão do gigante asiático ameaça a hegemonia dos Estados Unidos, e a relação entre os países é configurada por uma Guerra Comercial. Após a crise de 2008, as tensões comerciais entre EUA e China elevaram-se em virtude dos déficits americanos (CONDESSA, 2019). O conflito estende-se ainda para uma linha de frente tecnológica, onde a China enfrenta críticas concernentes à privacidade de dados e empresas chinesas sofrem retaliações a nível internacional.

Os obstáculos para a expansão tecnológica chinesa envolvem conflitos que expressam uma reconfiguração na dinâmica das relações entre países, trazendo o conceito da geopolítica dos dados como uma tendência crescente. As possibilidades para a China a partir da Rota da Seda Digital (DSR) e da Rota da Seda da Saúde ganham notoriedade. A DSR promove o desenvolvimento do setor de serviços digitais, como o comércio eletrônico e cidades inteligentes, e acelera o progresso tecnológico, incluindo computação, big data, internet das coisas, inteligência artificial, blockchain e computação quântica (TRIOLO \& GREENE 2020). Ao mesmo tempo, a Rota da Seda da Saúde auxilia a China a prestar ajuda a diferentes países em meio à crise sanitária. A China se adapta às novas condições impostas pelos desafios e continua a expandir sua influência. 


\title{
Rota da Seda para saúde e Rota da Seda digital em meio à crise
}

A pandemia mudou a abordagem da China em relação às suas prioridades político-econômicas, deslocando o foco para questões internas como "desemprego urbano, recuperação econômica doméstica imediata e manutenção do poder do Partido Comunista China (PCC)" (SINGH 2020). As vertentes da BRI são prioridades oito e nove na lista das dez primeiras de Xi Jinping, onde a preocupação maior se refere à preservação do poder do Partido Comunista, precedendo a prioridade em relação a manutenção da unidade nacional e a de expansão econômica. A partir dessa leitura sugere-se que, se necessário, Pequim não considerará a BRI tão importante quanto a estabilidade nacional política e social (THE DIPLOMAT 2020). No entanto, a retórica oficial de Pequim é que o surto pela covid-19 terá apenas um impacto temporário sobre sua política externa.

\begin{abstract}
Os projetos da Nova Rota da Seda se tornaram uma empresa grande demais para falir para a China, com custos irrecuperáveis significativos já comprometidos. E mais do que o investimento financeiro, Pequim também gastou um enorme capital político e de reputação em torno da iniciativa. Portanto, o governo irá persistir apesar das perspectivas sombrias, embora em uma escala mais moderada (PITLO 2020).
\end{abstract}

A perspectiva pessimista não elimina a possibilidade de novas áreas promissoras para a política externa chinesa. Uma pesquisa feita pela Silk Road Associates (SRA) em conjunto com a Baker Mackenzie aponta que, apesar dos impactos da crise sanitária, a BRI permanecerá sendo prioridade para o Governo Chinês. O estudo reforça ainda que as oportunidades surgem, acelerando o projeto da Digital Silk Road (DSR) e tornando propícia a implementação de projetos na área da Health Silk Road (HSR) (BOO, SIMPFENDORFER, RUAN \& DAVID 2020). Em 2017, o governo chinês patrocinou o seminário "Fórum da Belt and Road sobre Cooperação em Saúde: Rumo a uma Rota da Seda da Saúde", onde o Diretor Geral da OMS, Dr. Tedros Adhanom Ghebreyesus elogiou a proposta considerada visionária de Xi para utilizar a Belt and Road a fim de fortalecer a cooperação no setor da saúde (LANCASTER, HOOPER \& RUBIN). Ambas as rotas, que estão agora em evidência como oportunidade como Rota da Seda Digital e a Rota da Seda da Saúde, foram integradas a politica externa chinesa em 2017, e desde então a China tem construído a infraestrutura de telecomunicações, hospitais e instalações sanitárias numa perspectiva de maior conectividade sanitária e digital euroasiática. Há também formação médica e envio de equipes aos países membros da iniciativa (NAVAS 2020). A HSR, extensão da Masking diplomacy da China, forneceu assistência médica aos 
países participantes do BRI por meio de doações e consultas, e também por meio de exportações comerciais. Através da HSR, "a China busca limitar a perturbação econômica do surto, além de transferir sua experiência e know-how de combate à covid-19" (ZOU 2020).

O governo chinês forneceu ajuda médica e consulta em uma base
bilateral, muitas vezes entregue diretamente pelas embaixadas chinesas
locais, como as da Malásia, Filipinas e Grécia. Em outros casos,
suprimentos médicos foram fornecidos por empresas envolvidas em
projetos BRI no exterior, como a Huawei ou a China Communications
Construction Company. As fundações Jack Ma e Alibaba entregaram
pacotes de ajuda humanitária a dezenas de países, desde Uganda e
Ucrânia até os Estados Unidos (LANCASTER, HOOPER \& RUBIN).

Nesse sentido, a partir do aumento de plataformas de consulta médica como Alibaba Health, o setor MedTech da China poderá encontrar oportunidades internacionalmente. A Rota da Seda para Saúde também auxilia na construção da imagem da China agindo responsavelmente e de maneira colaborativa à crise e, internamente, fortalece a legitimidade do PCC. "Tecnologias semelhantes podem ser implementadas com sucesso no exterior se compostas por pessoas locais, devido às deficiências do setor de saúde em muitos países da BRI" (WORLD ECONOMIC FORUM 2020). Em países latino-americanos, por exemplo, a China prestou assistência médica para Cuba, Chile e Argentina, e realizou videoconferências com especialistas chineses e latino-americanos, incluindo países como Panamá e Costa Rica, para compartilhar lições aprendidas (OXFORD BUSINESS GROUP). As dificuldades dão lugar a novas iniciativas que reforçam a atuação chinesa no mundo.

\section{Efeitos da pandemia em países ao longo da BRI}

A verdadeira escala do impacto da covid-19 na economia global é impossível de avaliar no momento. O FMI atualmente prevê que 2020 verá a pior recessão desde 1930, embora os danos possam ser ainda maiores. O Banco Mundial apoiou uma iniciativa do G20 para suspender o pagamento da dívida dos países em desenvolvimento, e a China instou o Banco Mundial a "liderar pelo exemplo e fazer o mesmo" (SCHINDLER, JEPSON \& CUI 2020). O Banco Mundial também espera que 40 a 60 milhões de pessoas em todo o mundo mergulhem na pobreza extrema (GOULARD 2020). Dirigentes estão lidando com a crise em uma base amplamente nacional, mas os efeitos são globais. "Embora o ataque à saúde humana seja - esperançosamente - temporário, a turbulência política e econômica que o vírus desencadeou pode durar gerações" (KISSINGER 2020). Projeções 
estão sendo consideradas, graças aos efeitos já visíveis da atual conjuntura no curso da política externa Chinesa, principalmente no que concerne a financiamentos e a situação interna de países afetados pela crise. A pandemia pode tornar a BRI mais multilateral e menos chinesa. Para diluir riscos, a China pode ter que trabalhar mais com outros credores, e investidores.

Os esforços nesse sentido já começaram na pré-pandemia e provavelmente se expandirão ainda mais. Isso inclui a cooperação de mercado de terceiros com a China e o Japão, com cofinanciamento entre 0 Banco Asiático de Investimento em Infraestrutura liderado pela China e outras instituições multilaterais de crédito, como o Banco Asiático de Desenvolvimento liderado pelo Japão, o Banco Europeu para Reconstrução e Desenvolvimento e o Banco Mundial (SHEPPARD 2020).

Devido às restrições, outro reflexo da covid-19 foi na movimentação de equipamentos e materiais de construção, destacando-se a necessidade de diversificação da logística e da cadeia de suprimentos para uma melhor gestão da crise (OXFORD BUSINESS GROUP).

Um dos reflexos mais debatidos, por conseguinte, está em torno da dificuldade que enfrentarão os países ao longo da iniciativa Belt and Road em manter o compromisso com o pagamento de empréstimos concedidos pela China. A BRI precisará lidar com as dificuldades que enfrentam países em desenvolvimento, onde a batalha contra o vírus pode "inviabilizar os reembolsos de dívidas a governos, organizações internacionais e credores privados" (SCHINDLER, JEPSON \& CUI 2020). O corredor econômico China-Paquistão, por exemplo, possui mais de 20 projetos, finalizados e em andamento, envolvendo usinas termoelétricas, parques de energia eólica e solar, estações hidrelétricas assim como construção de rodovias e ferrovias (CPEC). No entanto, está prestes a sustentar uma perda de US \$ 8,2 bilhões, de acordo com uma avaliação preliminar do Banco de Desenvolvimento Asiático. A questão reflete o provável cenário de crises econômicas que atingirão principalmente países em desenvolvimento em um contexto durante e pós-pandemia. As empresas chinesas atingidas pelo coronavírus que executam contratos BRI podem contar com o apoio do Banco de Desenvolvimento da China na forma de "financiamento de baixo custo e empréstimos especiais de liquidez em moeda estrangeira" (TONCHEV 2020), mas há de se considerar que os bancos Chineses terão mais cautela antes de se envolver em projetos que possam acarretar prejuízo, assumindo uma postura mais exigente. Com as finanças domésticas limitadas para gastar em meio à pandemia, "a atividade de empréstimos do BRI estagnou, 
enquanto os investimentos empresariais se tornaram mais direcionados" (ZOU 2020).

A maioria dos devedores de baixa renda da China está na África e, de acordo com o banco mundial, $17 \%$ da dívida africana corresponde à China (TONCHEV 2020). Graças ao impacto da pandemia, quase 20 países africanos estão em sobre-endividamendo ou em alto risco de sobre-endividamento. $O$ relatório da China Africa Research Initiative (CARI) da Escola de Estudos Internacionais Avançados da Universidade Johns Hopkins constatou que, embora Pequim tenha cancelado dívidas no passado, a maioria eram empréstimos a juros zero, que representavam menos de $5 \%$ dos empréstimos chineses feitos à África. "Os empréstimos da China para a África totalizaram US \$ 152 bilhões entre 2000 e 2018, grande parte dos quais foram para projetos da Belt and Road Initiative" (NYABIAGE 2020).

É de se esperar, portanto, que o governo chinês, assim como empresas chinesas, continuem a ser pressionados a perdoar e renegociar dívidas. E, apesar da China não impor as mesmas condições econômicas exigidas pelo FMI ou pelo Banco Mundial, o processo de alívio da dívida não é automático. Em Pequim, um comitê liderado pelo Ministério das Finanças da China e envolvendo o Ministério do Comércio, o China Exim Bank e o China Development Bank considera cuidadosamente se os requerentes de alívio são realmente incapazes de pagar cada empréstimo (TONCHEV 2020). E como curso de ação para amenizar o golpe em países que participam da iniciativa, Pequim já suspendeu o pagamento de dívidas ao passo que explora outros caminhos, como a suspensão do pagamento de juros, alívio ou reestruturação (PITLO 2020).

Na Europa, as relações entre União Europeia (UE) e China no contexto da BRI permanecem sendo uma questão essencial. Até o final do ano de 2020, é prevista a assinatura do contrato de livre comércio intitulado Acordo Global de Investimento. O acordo, além de fomentar o comércio, facilitará investimentos entre os países e substituirá os tratados bilaterais de investimento existentes entre a China e a maioria dos membros da UE. Permitirá que as empresas europeias tenham mais acesso ao mercado chinês, sem a necessidade de joint ventures com parceiros chineses locais (GOULARD 2020). A Grécia, um dos países Europeus mais importantes pertencentes à iniciativa, continua confiante para avançar nas relações sino-gregas. No âmbito do novo projeto da Rota da Seda Marítima da China sob a BRI: 
A Grécia e o Porto de Pireu, que sob gestão chinesa se tornou o maior porto de contêineres do Mediterrâneo, fornecem um centro seguro para comerciantes e investidores chineses nos países da Europa central, meridional e oriental, bem como nos países do Mediterrâneo (XINHUA 2020).

Apesar das projeções otimistas e dos vários acordos atuais da BRI estarem progredindo, a crise gerou atrasos em projetos e dificultou a resolução de questões ainda em aberto. Além disso, líderes europeus ainda consideram ainda de extrema importância o resultado das eleições presidenciais estadunidenses para tomar decisões (GOULARD 2020). Esse fato sugere que os Estados Unidos continuam a representar influência significativa para os países europeus e, sob a liderança de Donald Trump, a China encontrará ainda maiores obstáculos para se estabelecer no mundo pós-covid.

Nos últimos 10 anos, o investimento chinês na América do Sul acelerou drasticamente, aumentando em mais de $480 \%$ entre 2008 e 2018, em comparação com apenas $89 \%$ no âmbito mundial. Mais da metade dos investimentos da China na América do Sul foram destinados a projetos de infraestrutura - particularmente em energia e transporte. Dos seis principais mercados de infraestrutura da América Latina (Brasil, México, Colômbia, Argentina, Peru e Chile), apenas Peru e Chile aderiram formalmente à BRI, enquanto os outros países como o Brasil, continuam recebendo investimentos chineses significativos sem acordos formais com a política externa chinesa (DABUS \& BASU, 2020). Muitos projetos apoiados pela China enquadrados como parte da BRI precisaram parar em toda a região, já que a crise da covid-19 afetou a manufatura, as cadeias de abastecimento e o movimento de pessoas e mercadorias. Houve menos novos projetos de infraestrutura chineses na América Latina em 2020, e nenhum país novo fora incluído na política externa chinesa (KOOP 2020). Além dos impactos da pandemia, a adesão a BRI é dificultada pela má distribuição de riscos em certos pontos como os discernentes a questões ambientais. Na Argentina, a construção de barragens hidrelétricas começou sem uma avaliação de impacto ambiental, resultando na interrupção do projeto pelo Supremo Tribunal. Os planos de refinaria de petróleo da refinaria chinesa Sinopec em Moín, na Costa Rica, enfrentaram obstáculos institucionais semelhantes: a secretaria nacional do meio ambiente do país rejeitou a primeira avaliação do projeto devido a omissões questionáveis. Projetos de infraestrutura chineses também enfrentaram oposição popular. $O$ projeto hidrelétrico de Rositas, na 
Bolívia, por exemplo, não conseguiu superar a oposição das comunidades locais ao deslocamento de suas terras (DABUS \& BASU, 2020).

\section{Impactos da nova lei de segurança nacional em Hong Kong para a China no mundo}

Os obstáculos referentes à pandemia não são os únicos postos à China em 2020. A Lei de Segurança Nacional imposta por Pequim para Hong Kong gera maior complexidade nas relações da China com o mundo. Para muitos analistas, a entrada em vigor da legislação representa o fim da autonomia relativa a qual Hong Kong desfrutava após 156 anos de colonização britânica. Pelo modelo "um país, dois sistemas", a Lei Básica da cidade previa autonomia política, administrativa e judicial em relação a Pequim por um período de 50 anos, mas o teor da nova legislação, entre outros pontos, proíbe indivíduos de se posicionar de forma contrária ao governo chinês. O projeto dessa lei inclui a criação de novas unidades de polícia em Hong Kong, e fornece poderes ao governo chinês para apontar juízes que cuidarão dos casos envolvendo a segurança nacional, o que tira a independência do Judiciário do território semiautônomo. Pelos termos da lei, mandados judiciais não serão mais necessários para a realização de buscas em lugares suspeitos, e pessoas sob investigação poderão ser impedidas de sair da cidade. Agentes de segurança de Pequim poderão atuar abertamente na cidade, utilizando ferramentas de monitoramento como grampos telefônicos. Suspeitos de crimes contra a segurança nacional poderão ser presos sem direito à fiança. Estados Unidos, Japão e Taiwan questionaram a aprovação da lei e os EUA disseram considerar que "a mudança acaba com o status especial de Hong Kong, o que abre espaço para retirada de vantagens comerciais que a região possui em áreas como transferência de tecnologia e vendas de equipamentos militares" (FOLHA DE SÃO PAULO 2020). As críticas que pairam sobre o tema impõem uma série de desconfianças sobre a China.

Há pouco menos de um quarto de século, Pequim convidou a comunidade internacional a tratar Hong Kong como algo separado da China continental. Como uma região autônoma que respeitava o estado de direito e protegia os direitos humanos, Hong Kong desfrutou de acordos comerciais especiais, acordos alfandegários e imigração global que ajudaram a tornar a cidade uma capital das finanças internacionais, sua economia uma das mais livres do mundo. Todas essas conquistas estão agora em risco (DAVIS 2020).

O fato denota os pontos de inflexibilidade da China em relação às divergências com a maior parte do mundo ocidental democrático e reforça a 
narrativa existente de que as ambições chinesas são uma ameaça para democracias. Sob o presidente Xi Jinping, o governo chinês expandiu amplamente serviços inteligentes em território nacional, alimentando uma nova geração de empresas que fabricam tecnologia sofisticada a preços cada vez mais baixos, e o sistema de tecnologia chinês é acusado de não respeitar a privacidade de indivíduos, exportando uma ferramenta altamente eficaz para a repressão política para outros governos. Hoje, 18 países - incluindo Zimbábue, Uzbequistão, Paquistão, Quênia, Emirados Árabes Unidos e Alemanha - estão usando sistemas de monitoramento inteligentes feitos na China (THE NEW YORK TIMES 2019). O debate o qual possui no centro a desconfiança em relação às cidades inteligentes chinesas se fortalece, mas parece não impedir que a China continue a expandir sua capacidade tecnológica internacionalmente. Dos 1.000 projetos de cidades inteligentes que estão sendo construídos atualmente em todo o mundo, a China abriga metade deles. Na cidade de Hangzhou, o sistema de inteligência artificial City Brain, criado pela empresa chinesa Alibaba, usa Big Data e grande poder computacional para melhorar e corrigir problemas de tráfego. O que diferencia os sistemas inteligentes em cidades de outros países como Barcelona, é justamente a garantia em relação à privacidade de dados (LANTAU BRASIL 2020).

\title{
Oportunidades e obstáculos para o crescimento tecnológico chinês
}

\begin{abstract}
"Apenas alguns meses atrás, as ambições de tecnologia da China pareciam ameaçadas pela covid-19, mas a pandemia proporciona hoje novas oportunidades para a ascensão da China como potência tecnológica e fornecedora global de infraestrutura digital. De fato, nos próximos meses e anos, a Digital Silk Road (DSR) da China apenas se acelerará e se expandirá" (BLANCHETTE \& HILLMAN, 2020).
\end{abstract}

Pequim está usando a Rota da Seda Digital, um subconjunto da Belt and Road Initiative, para melhorar a conectividade digital no exterior, para estender sua influência e promover a ascensão da China como uma superpotência tecnológica (VOX 2019). O projeto é composto por quatro componentes inter-relacionados com foco tecnológico. Primeiro, a China está investindo em infraestrutura digital no exterior, incluindo redes celulares de próxima geração, cabos de fibra óptica e data centers. Em segundo lugar, a iniciativa contém um foco doméstico no desenvolvimento de tecnologias avançadas que serão essenciais para o poderio econômico e militar global, incluindo sistemas de navegação por satélite, inteligência artificial e computação quântica. Em terceiro lugar, a DSR promove o comércio eletrônico por meio de zonas de livre comércio digital, que reduzem barreiras 
comerciais transfronteiriças e possibilita centros logísticos regionais. Quarto, a China está trabalhando para estabelecer seu ambiente digital internacional modelo por meio da diplomacia digital e da governança multilateral. Isso incluiu o uso de instituições multilaterais para estabelecer padrões tecnológicos relacionados à infraestrutura de telecomunicações e promover o princípio de cibersoberania em fóruns da ONU (CFR 2020). Com base na infraestrutura digital, a China está construindo diversos sistemas de serviços inteligentes que capacitam áreas de assistência médica, educação, transporte, alimentação, entretenimento e promovem novos tipos e modelos de negócios (NDRC 2020). O China Science daily, por exemplo, desenvolveu conjuntamente com pesquisadores da Universidade de Pequim um software para gerar notícias sobre as últimas descobertas das principais revistas científicas do mundo. De acordo com seus inventores, o robô-repórter gerou mais de 200 reportagens baseadas nos resumos em inglês de teses publicadas em revistas como Science, Nature, Cell e New England Journal of Medicine. Antes da publicação, os artigos gerados automaticamente passam por um processo de revisão, e um grupo de cientistas e editores verificam o conteúdo ou fornecem informações suplementares (XINHUA 2019). O desenvolvimento de tecnologia também influencia diretamente a construção da infraestrutura trazendo inovação para diversas áreas essenciais. Os portos, um dos alvos principais da iniciativa chinesa e especificamente da DSR, são um exemplo e evoluem ao passo que aprimoram o desenvolvimento tecnológico nas operações logísticas. A tecnologia da Internet das Coisas (IoT) e o Big Data tomam o seu lugar na dianteira das tendências tecnológicas que irão fazer nascer uma nova geração de ecossistemas portuários (RIBEIRO, PINHO \& METELO 2016).

A tecnologia está no centro do debate sobre o futuro e, portanto, estreitamente atrelada a conflitos geopolíticos.

As lacunas postas pela exclusão digital são justamente o espaço que a Rota da Seda Digital busca preencher e isso representa uma oportunidade para a China desafiar o controle dos EUA no comércio global e expandir sua presença em países periféricos. A gigante chinesa da internet, Tencent, por exemplo, tornou-se em 20 anos o segundo maior conglomerado de tecnologia da China, atrás apenas do Alibaba. Avaliada em US\$ 348 bilhões, estreou em 2018 no mercado brasileiro com um aporte de US\$180 milhões no Nubank e transformou a fintech na startup mais valiosa da América Latina. No cardápio de negócios oferecido pela Tencent aos chineses há o $Q Q$, um aplicativo de mensagem instantânea, a Tencent Music e o aplicativo WeChat (ESTADÃO 2020).

Estima-se que o fundo da Tencent Holdings tenha investido US\$ 30 bilhões em empresas pelo mundo entre 2015 e 2017. A história da companhia teve início em 
1998 e em 2004 abriu capital em Hong Kong, garantindo até o ano passado um retorno de $67.000 \%$ aos acionistas (ESTADÃO 2020). O objetivo da empresa é se consolidar cada vez mais como uma gigante do entretenimento com redes sociais, jogos, música e esportes. A empresa é responsável por mais de $50 \%$ do mercado de social ads na china, por $15 \%$ de todo o faturamento global com jogos digitais em 2018, é dona de mais de 60\% do mercado musical chinês além de possuir plataformas de streaming que são acessadas por milhões de usuários na China (ROCKCONTENT 2019). Os dados fornecidos à empresa pelos usuários de seus produtos se transformam em tecnologias e estratégias para permanecer expandindo.

A captura de dados de bilhões de pessoas no mundo durante as últimas décadas foram expressivamente dominadas por empresas estadunidenses como a Facebook e Google. Considerando as possibilidades inesgotáveis que esses dados representam, é evidente a concentração de poder atrelada a eles. Dados são informações úteis coletadas para apoiar a tomada de decisões, podem fornecer evidências incontestáveis, permitem que as organizações meçam a eficácia de uma determinada estratégia e visualizem as relações entre o que acontece em diferentes locais, departamentos e sistemas. Atualmente, empresas tecnológicas nãoamericanas surgem, expandem sua tecnologia de maneira significativa, e ganham maior espaço no mercado mundial e no mercado interno americano. Essas empresas são chinesas e contribuem para a relação conturbada entre as duas potências contemporâneas no sistema internacional, demonstrando a nova geopolítica das redes e a importância dada no acesso a dados.

Essa dinâmica tende a ser uma prévia de como se reconfigurarão as relações entre países em um futuro não tão longínquo. Em tradução livre para o significado original, "Data is the new oil" como "Os dados são o novo petróleo" é uma expressão usada em todo o mundo. Líderes nesse segmento estão a Alphabet, considerada a companhia mãe do Google, Amazon, Apple, Facebook e Microsoft. As cinco corporações mais valiosas do mundo parecem imparáveis quando o assunto é tecnologia e captura de dados. Coletivamente, as empresas reuniram mais de 25 bilhões de dólares de lucro líquido no primeiro trimestre de 2017. A Amazon detém metade de todos os dólares gastos online nos Estados Unidos. Google e Facebook contabilizaram quase toda a receita de crescimento em propaganda digital nos Estados Unidos em 2019. "Este domínio gerou pedidos para que as gigantes de tecnologia fossem divididas, como ocorreu com a Standard Oil no começo do século XX" (BAKER TILLY BRASIL 2020). 
Os dados permitem que empresas compreendam mais e melhor a respeito do perfil de consumidores e, consequentemente, constituem uma porta de entrada para influenciá-los econômica e politicamente. A geração de relatórios sobre indivíduos a partir de um volume extremamente alto de dados retrata uma revolução para a sociedade e envolve uma disputa por riqueza e poder. Diante desse contexto, o mais recente fator de tensão entre EUA e China envolve o aplicativo chinês Tik Tok, disponível em 150 países e 75 idiomas. Na Índia, seu principal mercado, quase um terço da população faz uso do aplicativo e a mesma porcentagem se aplica aos Estados Unidos. O sucesso do Tik Tok fez da ByteDance, a empresa criadora, uma das startups mais atrativas do mundo, valendo 67 bilhões de euros (SANTIRSO 2020). O mesmo sucesso fez com que o aplicativo fosse alvo de críticas pela administração Trump, que acusa o Tik Tok de atuar como ferramenta de espionagem do governo chinês, interferindo na segurança nacional. O resultado até então fora um acordo entre duas empresas americanas, Oracle e Walmart, que comprarão $20 \%$ do aplicativo nos EUA, formando uma nova empresa batizada como TikTok Global (VALOR INVESTE 2020).

O conflito entre Estados Unidos e China faz parte de um contexto ainda mais amplo. Com o argumento de que busca proteger os produtores norte-americanos e reverter o déficit comercial que os Estados Unidos têm com a China, Donald Trump vem anunciando desde 2018 tarifas sobre produtos importados do país asiático. $\mathrm{O}$ objetivo é dificultar a chegada de produtos chineses aos Estados Unidos, o que estimularia a produção interna. O governo da China, por sua vez, tem reagido a esses anúncios com retaliações, chegando a impor também tarifas sobre produtos norte-americanos (TREVISAN 2019). A rápida ascensão chinesa é vista como uma ameaça à hegemonia norte-americana e além de impor tarifas adicionais sobre os produtos chineses importados, os EUA também estão endurecendo as restrições à transferência de tecnologia para a China e às atividades comerciais de algumas empresas chinesas de alta tecnologia (KWAN 2019). Um relatório divulgado em 2012 pelo Comitê Permanente de Inteligência dos EUA identificou a Huawei e a ZTE, empresa líder em telecomunicações e tecnologia da informação, como ameaças potenciais à segurança (THE WASHINGTON POST 2019). A Huawei tem enfrentado, portanto, acusações dos Estados Unidos e seus aliados, de que seu equipamento permite a vigilância do governo chinês. A Huawei afirmou que seus produtos não representam maior risco de cibersegurança do que os de qualquer outro fornecedor e que não há evidências de alegações de espionagem nos Estados 
Unidos. A empresa fez ainda parceria com autoridades britânicas para auditar seus produtos. O presidente Donald Trump estendeu uma ordem executiva proibindo as empresas americanas de trabalhar com ou comprar equipamentos de telecomunicações de empresas consideradas um risco à segurança nacional até maio de 2021 (GARTENBERG 2020).

A animosidade entre os EUA e a China intensificou-se em meio à pandemia, momento o qual Donald Trump começou a se referir à covid-19 como um "vírus chinês" e autoridades americanas e britânicas acusaram repetidamente que a China inibiu uma resposta global combinada ao reter informações importantes sobre a covid-19. A tensão aumentou ainda mais quando Washington fechou o consulado chinês em Houston e Pequim fechou o consulado americano em Chengdu (SCHINDLER, JEPSON \& WENXING 2020). Como reflexo da tensão, as empresas de tecnologia passam a se destacar e grande parte do debate europeu sobre o lado digital da Belt and Road Initiative da China se concentra estreitamente no papel da Huawei nas redes $5 \mathrm{G}$ do continente e nas vendas de equipamentos de vigilância chineses. A Huawei fornece tecnologia para rede 5G, a próxima (quinta) geração de conectividade muito mais veloz, com maior cobertura e conexões mais estáveis. Especialistas dizem que o 5G pode conseguir navegação e downloads até 20 vezes mais rápido (BBC BRASIL 2019). A Huawei relata que gastou US\$ 15 bilhões (R\$ 65,5 bilhões) no ano de 2019 em pesquisa para alcançar a liderança de mercado, e defende que os Estados Unidos querem frustrar seu crescimento porque as empresas norte-americanas não conseguem oferecer a mesma gama de tecnologia a um preço competitivo (SPUTINIK BRASIL 2020).

\section{Considerações finais}

A pandemia causará uma recessão global em 2020, que poderá ser pior do que a crise financeira global de 2008-2009, de acordo com o Fundo Monetário Internacional (AGENCIA BRASIL 2020). Antever que a presença da China no mundo pós-pandemia continuará a desempenhar papel crucial, passa ser uma tendência provável, principalmente pelo destaque em áreas-chave como a de alta tecnologia. Com a economia chinesa se contraindo no primeiro trimestre de 2020, o capital chinês será provavelmente mobilizado para atender às necessidades internas no curto prazo, o que pode se traduzir em uma redução de investimentos na BRI. Ainda em janeiro, no início da pandemia, a China era vista como um foco de problema e preocupação. Passados três meses, o país passou a figurar como modelo para 
muitas das estratégias empregadas no combate ao coronavírus e também como provedor de insumos médicos indispensáveis (CHARLEAUX 2020). A estratégia da Rota da Seda da Saúde encontra, portanto, espaço para expandir sua influência em meio à crise sanitária, e muitos países como Itália, Estados Unidos e Cuba, contaram com equipamentos médico-hospitalares e doações advindas da China. $O$ país está também intensificando seu foco na Rota da Seda Digital (DSR). Os projetos de infraestrutura da DSR são cada vez mais vistos como uma maneira de Pequim aumentar sua influência em países emergentes e em desenvolvimento, e como uma oportunidade para empresas de tecnologia nacionais, como Alibaba e Tencent, expandirem seus negócios globais (TRIOLO, BROWN, ALLISON, BRODERICK 2020). Durante a pandemia, a DSR vem crescendo, uma vez que vários países estão usando soluções digitais inspiradas nas soluções da China para combater a Covid-19. As tecnologias digitais como big data, blockchain e 5G, desempenham papel de apoio para otimização do sistema de saúde pública, diminuem as lacunas de exclusão digital no mundo, e aproveitam novas fontes de crescimento econômico (NDRC).

Desde que Xi anunciou sua iniciativa em 2013, a China tem concedido ou prometido centenas de milhões de dólares em empréstimos ou subsídios para a construção de usinas de geração de energia elétrica, gasodutos, portos, aeroportos e ferrovias em 138 países da África, da Ásia, da Europa e da América Latina (NAVAS 2020). No entanto, a crise reconfigura o cenário em vários territórios, o que afeta diretamente a situação interna de parceiros da BRI. No curto prazo, espera-se que muitos países tentem reestruturar seus empréstimos e obrigações financeiras com a China, e à medida que as economias ao redor do mundo embarcam em iniciativas de recuperação da pandemia, a China se tornará ainda mais necessária (MARDEL 2020). Atualmente, como resultado da pandemia, vários países, incluindo Paquistão e várias nações africanas solicitaram à China que adie ou perdoe os pagamentos de dívidas. O G20 concordou em permitir que 73 nações suspendessem os pagamentos do juro da dívida até o final de 2020 (NAVAS 2020). A aprovação da Lei de Segurança Nacional para Hong Kong é um dos obstáculos para a China, que entra em rota de colisão com os Estados Unidos, União Europeia e o Reino Unidos. Washington, por exemplo, advertiu que retiraria o status especial comercial conferido a Hong Kong, por considerar que a nova lei elimina o alto grau de autonomia do enclave decidido entre Pequim e Londres nas negociações de transferência da soberania (LIY 2020). Apesar dos obstáculos, todas as articulações 
da China denotam o interesse em continuar estimulando a cooperação internacional e avançando nos projetos referentes à BRI.

Os principais atores da iniciativa Belt and Road são bancos comerciais chineses, firmas comerciais, plataformas de comércio eletrônico, empresas de telecomunicações, prestadores de serviços logísticos e empresas de transporte. Nos próximos anos, eles podem fortalecer suas posições no mercado global, com o apoio do governo chinês, por meio de novas e aprofundadas parcerias estratégicas com empresas e governos não chineses (GOULARD 2020).

Em comparação com os enormes projetos de transporte e energia que dominaram os primeiros anos do BRI, os projetos de tecnologia da informação e comunicação geralmente têm custo mais baixo, são mais fáceis de entregar e mais fáceis de monetizar. Esses atributos os tornam menos arriscados e mais atraentes para os investidores (BLANCHETTE \& HILLMAN, 2020) e fortalecem avanços tecnológicos que serão mais necessários no mundo pós-pandemia. Oportunidades para empresas de comércio eletrônico e fintech surgem mas as preocupações de segurança levantadas em relação ao trabalho com empresas de tecnologia chinesas como Huawei, Tencent e Alibaba podem representar obstáculos na expansão dos negócios para outros países com iniciativas BRI. Ganhar confiança é fundamental para a China conquistar uma fatia maior dos mercados (PITLO 2020), evitando que as limitações impostas às empresas não só nos Estados Unidos, mas também em outros países como o Japão e a França que pode em breve restringir o uso de equipamentos fabricados pela Huawei para sua rede 5G, por exemplo, continuem crescendo. Somado ao contexto de guerra comercial entre a China e os Estados Unidos que também faz parte da realidade dos países desde o início de 2018 e caminha hoje a passos lentos para uma solução, sem garantias para os próximos anos, a conturbada cena entre as duas potências ainda resguarda um futuro incerto.

Sendo assim, previsões de como o mundo pós-pandemia será configurado dependem dos efeitos da crise sanitária, que ainda não podem ser medidos por completo, e do curso dos acontecimentos políticos que envolvem as grandes potências contemporâneas. É inegável que constrói-se hoje a imagem de uma China fortalecida, capaz de ditar os protocolos técnico-sanitários e liderar uma retomada econômica no mundo. E se o país conseguir responder à altura às questões de confiabilidade por parte de outros países, a China será capaz de aumentar ainda mais sua presença através da iniciativa Belt and Road e se mantendo na liderança em novas tecnologias, que já revolucionam a maneira como se vive hoje. 


\section{REFERÊNCIAS}

AGENCIA BRASIL 2020: Pandemia causará recessão global em 2020, diz FMI. Agência Brasil, 2020. Disponível em: https://agenciabrasil.ebc.com.br/economia/noticia/202003/pandemia-causara-recessao-global-em-2020-diz-fmi Acesso em: 4 de Setembro de 2020.

AMARAL 2019: AMARAL, Olavo: Rota da Seda. Piauí, Folha da São Paulo, 2019. Disponível em: https://piaui.folha.uol.com.br/materia/rota-da-seda/ Acesso em: 12 de Julho de 2020.

BAKERTILLY 2020: Dados: o novo petróleo do mundo e combustível para o futuro. Bakertilly, 2020. Disponível em: https://bakertillybr.com.br/dados-novo-petroleo/ Acesso em: 25 de Julho de 2020.

BLANCHETTE \& HILLMAN 2020: BLANCHETTE, Jude \& HILLMAN, Jonathan: China's Digital Silk Road after the coronavirus. Center for Strategic and International Studies, 2020. Disponível em: https://www.csis.org/analysis/chinas-digital-silk-road-after-coronavirus Acesso em: 28 de Julho de 2020.

BRAUTIGAM 2020: BRAUTIGAM, Deborah. Chinese Debt Relief: Fact and Fiction. The diplomat, 2020. Disponível em: https:/thediplomat.com/2020/04/chinese-debt-relief-fact-andfiction/ Acesso em: 22 de Julho de 2020.

BUSINESS REPORTING DESK 2020: Business Reporting Desk: Impact of covid-19 on Belt and Road Initiative. Belt and Road news, 2020. Disponível em: https://www.beltandroad.news/2020/08/01/impact-of-covid-19-on-belt-road-initiative/ Acesso em: 8 de Agosto de 2020.

BRI NEWS: Belt and Road Initiative and the covid-19 Emergency. Belt and Road news, 2020 Disponível em: https://www.beltandroad.news/2020/07/19/chinas-belt-and-road-initiativeand-the-covid-19-emergency/ Acesso em 21 de Agosto de 2020.

BOO, SIMPFENDORFER, RUAN \& DAVID 2020: BOO, Bee Chun, SIMPFENDORFER, Ben, RUAN, Zhenyu DAVID, Martin: Understanding how covid-19 alters BRI. Baker Mckenzie, 2020. Disponível em: https://www.bakermckenzie.com//media/files/insight/publications/2020/03/covid19-bri-short-report.pdf?la=en Acesso em: 14 de Agosto de 2020.

CFR 2020 - Council on Foreign Relations: Exporting Authoritarianism. Council on Foreign Relations, 2020. Disponível em: https://www.cfr.org/podcasts/exporting-authoritarianism Acesso em: 1 de Julho de 2020.

CHARLEAUX 2020 - CHARLEAUX, João Paulo: Qual o papel que a China assume em meio à pandemia? Disponível em: https://www.nexojornal.com.br/expresso/2020/04/11/Qual-opapel-que-a-China-assume-em-meio-\%C3\%A0-pandemia Acesso em: 18 de Maio de 2020.

CPEC: Projects Progress Update. China Pakistan Economic Corridor. Disponivel em: http://www.cpec.gov.pk/progress-update Acesso em: 15 de Setembro de 2020.

DABUS \& BASU 2020: DABUS, André \& BASU, Meghna: O Belt and Road da China chega à América Latina. Marsh, 2020.2 Disponível em:https://www.marsh.com/br/insights/research/o--belt-and-road--da-china-chega-a-americalatina.html Acesso em: 20 de Setembro de 2020.

DAVIS 2020 - DAVIS, Michael, C. :Hong Kong is part of the mainland now. Foreign Affairs, 2020. Disponível em: https://www.foreignaffairs.com/articles/china/2020-07-02/hong-kongpart-mainland-now Acesso em: 02 de Agosto de 2020. 
ESTADÃO 2020: China procura ajuda de Alibaba e Tencent para monitorar coronavírus com QR code. Estadão, 2020. Disponível em: https://link.estadao.com.br/noticias/empresas, china-procura-ajuda-de-alibaba-e-tencentpara-monitorar-coronavirus-com-qr-code,70003200583 Acesso em: 10 de Julho de 2020.

FOLHA DE SÃO PAULO 2020: China sanciona Lei de Segurança para Hong Kong e grupos de protestos encerram atividades. Folha de São Paulo, 2020. Disponível em: https://www1.folha.uol.com.br/mundo/2020/06/china-aprova-lei-de-seguranca-nacional-parahong-kong.shtml Acesso em: 13 de Agosto de 2020.

GOMBATA 2020: Marsília Gombata : Pandemia congela planos da Nova Rota da Seda na América Latina. Econômico Valor, 2020. Disponível em : https://valor.globo.com/mundo/noticia/2020/08/25/pandemia-congela-planos-da-nova-rotada-seda-na-america-latina.ghtml Acesso em: 30 de Agosto de 2020.

GOULARD 2020 : GOULARD, Sebastian: Recovering from covid-19 and developing new priorities for the BRI. Belt and Road Europe, 2020. Disponível em: https://www.oboreurope.com/en/belt-road-video-conference/ Acesso em: 13 de Julho de 2020.

GRIFFITHS 2017: GRIFFITHS, James: China's new world order: Xi, Putin and others meet for Belt and Road Forum. CNN, 2017. Disponível em: https://edition.cnn.com/2017/05/13/asia/china-belt-and-road-forum-xi-putinerdogan/index.html Acesso em: 18 de Agosto de 2020.

ITAKURA, Ken: Evaluating the impact of US-China trade war. Asian Economic Policy Review, 2019. Disponível em:https://onlinelibrary.wiley.com/doi/full/10.1111/aepr.12286 Acesso em: 10 de Julho de 2020.

KISSINGER: KISSINGER, Henry A.: The coronavirus pandemic will forever alter the world order. Wall Street Journal, 2020. Disponível em: https://www.wsj.com/articles/thecoronavirus-pandemic-will-forever-alter-the-world-order-11585953005 Acesso em: 27 de Julho de 2020.

KOOP 2020: KOOP, Fermín: Coronavírus reestrutura Iniciativa Cinturão e Rota na América Latina. Diálogo Chino, 2020. Disponível em: https://dialogochino.net/pt-br/infraestrutura-ptbr/36699-coronavirus-reestrutura-iniciativa-cinturao-e-rota-na-america-latina/ Acesso em: 21 de Agosto de 2020.

KWAN, Chi Hung: The China-US trade war: Deep-Rooted Causes, Shifting Focus and Uncertain Prospects. Asian Economy Policy Review, 2019 Disponível em: https://onlinelibrary.wiley.com/doi/full/10.1111/aepr.12284 Acesso em: 11 de Setembro de 2020.

LANCASTER, RAPP-HOOPER \& RUBIN - LANCASTER, Kirk, RAPP-HOOPER, Mira, RUBIN, Michael: Mapping China's Silk Road. Council on Foreign Relations, 2020. Disponível em: https://www.cfr.org/blog/mapping-chinas-health-silk-road Acesso em: 9 de Agosto de 2020.

LANTAU BRASIL 2020: Cidades inteligentes ou cidades de vigilância. Lantau Brasil, 2020. Disponível em: https://www.lantau.com.br/post/cidades-inteligentes-ou-cidades-devigil\%C3\%A2ncia Acesso em: 18 de Agosto de 2020.

LAURENTIU 2020: LAURENTIU, Gagu: The Belt and Road Initiative in the contexto of the covid-19. Acta Universitatis Danubius, 2020. Disponível em: http://dj.univdanubius.ro/index.php/AUDRI/article/view/335 Acesso em: 06 de Setembro de 2020.

LIY 2020 - LIY, Macarena Vidal: China promulga a lei de segurança para reprimir dissidência em Hong Kong. El País, 2020. Disponível em: https://brasil.elpais.com/internacional/2020-06-30/china-promulga-a-lei-de-seguranca-parareprimir-dissidencia-em-hong-kong.html Acesso em: 25 de Junho de 2020. 
LUGT\& WANG: Sanne van der Lugt \& Duanyong Wang: The Impact of covid-19 Coronavírus on the Belt and Road Initiative. Belt and Road Research Platform, 2020. Disponível em: https://www.beltroadresearch.com/coronavirus-belt-and-road/ Acesso em: 19 de Setembro de 2020.

MARDELI 2020 - MARDELLI, Jacob : The BRI in Bangladesh Walking the tightrope between Beijing and Delhi. Mercis, 2020. Disponível em:https://merics.org/en/belt-and-road Acesso em: 14 de Julho de 2020.

MARDEL, PUTTEN 2020 - SHEPARD, Wade, MARDEL, Jacob, PUTTEN, Frans-Paul van der: The future of China's Belt and Road after the Coronavirus Pandemic. On the silk Road, 2020. Disponível em: https://newsilkroad.substack.com/p/the-future-of-chinas-belt-and-road Acesso em: 28 de Junho de 2020.

MOZUR, KESSEL \& CHAN 2019- MOZUR, Paul, KESSEL, Jonah M \& CHAN, Melissa: Made in China, Exported to the World: The Surveillance State. The new york times, 2019. Disponível em: https://www.nytimes.com/2019/04/24/technology/ecuador-surveillancecameras-police-government.html Acesso em: 5 de Julho de 2020.

MOZUR 2020 - MOZU, Paul: O que está por trás do WeChat, o aplicativo mais usado da China. Estadão, 2020. Disponível em: https://link.estadao.com.br/noticias/cultura-digital,oque-esta-por-tras-do-wechat-o-aplicativo-mais-usado-na-china,70003443393 Acesso em: 21 de Setembro de 2020.

NAVAS 2020: NAVAS, María Helena: Nova Rota da Seda: Como a pandemia de novo coronavírus ameaça a maior iniciativa de política externa da China. Epoca, 2020. Disponível em:https://epoca.globo.com/mundo/nova-rota-da-seda-como-pandemia-de-coronavirusameaca-maior-iniciativa-de-politica-externa-da-china-24494090 Acesso em: 18 de Agosto de 2020.

NYABIAGE 2020: NYABIAGE, Jevans: China's promise of loan write-offs for distressed African nations barely dents a much bigger debt crisis. China diplomacy, 2020. Disponível em: https://www.scmp.com/news/china/diplomacy/article/3089856/chinas-promise-loan-writeoffs-distressed-african-nations Acesso em: 23 de Julho de 2020.

NDRC 2007 - Program of Action for Sustainable Development in China in the Early 21st Century. National Development and Reform Comission - People's Republic of China, 2007. Disponível em: https://en.ndrc.gov.cn/newsrelease_8232/200702/t20070205_1193884.html Acesso em: 28 de Julho de 2020.

NDRC 2020 - Digital Silk Road Assists Africa in Combating COVID-19. National Development and Reform Comission - People's Republic of China, 2007. Disponível em: https://en.ndrc.gov.cn/newsrelease_8232/202006/t20200601_1229673.html Acesso em: 2 de Setembro de 2020.

NDRC 2020 : Digital Trade is Becoming a New Engine for the Development of the Belt and Road. National Development and Reform Comission - People's Republic of China, 2007. Disponível

em: https://so.ndrc.gov.cn/s?siteCode=BM04000007en\&token=\&qt=digital+silk+road Acesso em: 7 de Julho de 2020

OXFORD BUSINESS GROUP 2020: How will the international covid-19 outbreak impact the Belt and Road Initiative? Disponível em: https://oxfordbusinessgroup.com/news/how-willinternational-covid-19-outbreak-impact-belt-and-road-initiative Acesso em: 15 de Agosto de 2020.

PAULSON 2018 - PAULSON H. M. : Remarks by Henry M. Paulson, Jr., on the United States and China at a crossroads. Paulson Institute, 2019. Disponívell em: 
https://www.paulsoninstitute.org/press_release/remarks-by-henry-m-paulson-jr-on-theunited-states-and-china-at-a-crossroads/ Acesso em: 27 de Julho de 2020.

PERLEZ \& HUANG 2017: PERLEZ, Jane \& HUANG, Yufan: Behind China's \$1 trillion plan to shake up the economic order. The New York Times. 2017. Disponível em: https://www.nytimes.com/2017/05/13/business/china-railway-one-belt-one-road-1-trillionplan.HTML Acesso em: 15 de Julho de 2020.

PITLO 2020 - PITLO, Lucio Blanco: How the coronavirus pandemic could lead to a less chinese Belt and Road Initiative. South China Morning Post, 2020. Disponível em: https://www.scmp.com/week-asia/opinion/article/3083008/how-coronavirus-pandemic-couldlead-less-chinese-belt-and-road Acesso em: 10 de Julho de 2020.

ROCKCONTENT 2019: A gigante empresa chinesa Tencent ganha cada vez mais espaço no mercado digital. Disponível em: https://inteligencia.rockcontent.com/tencent/ Acesso em: 10 de Agosto de 2020.

SANTOS 2019 - SANTOS, Claudia: A cronologia da guerra comercial entre Estados Unidos e China. O globo, 2019. Disponível em: https://oglobo.globo.com/economia/a-cronologia-daguerra-comercial-entre-estados-unidos-china-23901049 Acesso em: 21 de Julho de 2020.

SANTIRSO 2020 - SANTIRSO, Jaime: O lado obscuro do Tik Tok, a rede social chinesa dos vídeos curtos. El País, 2020. Disponível em: https://brasil.elpais.com/tecnologia/2020-0119/o-lado-escuro-do-tiktok-a-rede-social-chinesa-dos-videos-curtos.html Acesso em: 5 de Agosto de 2020.

SOERGEL 2018 - SOERGEL, Andrew: What Makes a City Smart? U.S. news, 2018. Disponível em: https://www.usnews.com/news/economy/articles/2018-01-12/at-ces-expertswrestle-with-what-makes-a-city-smart Acesso em: 20 de Agosto de 2020.

SCHINDLER, JEPSON \& CUI: SCHINDLER, Seth, JEPSON, Nicholas \& CUI, Wenxing: Covid-19 and the future of global development. Science Direct, 2020. Disponível em: https://www.sciencedirect.com/science/article/pii/S2590051X20300095\#fn0005 Acesso em: 03 de Setembro de 2020.

SINGH 2020: SINGH, Swapnil: China's Belt and Road Initiative and the covid-19 Emergency. Iventiva, 2020. Disponível em: inventiva.co.in/stories/swapnil/chinas-belt-and-road-initiativeand-the-covid-19-emergency/ Acesso em: 8 de Agosto de 2020.

SHEN 2018 - SHEN, Hong: Building a digital silk road? Situating the internet in China's Belt and Road Initiative. International Journal of Communication, 2020. Disponível em: https://ijoc.org/index.php/ijoc/article/view/8405 Acesso em: 16 de Julho de 2020.

TONCHEV 2020: TONCHEV, Plamen: The Belt and Road after covid-19. The Diplomat, 2020. Disponível em: http://www.viet-studies.com/kinhte/BeltRoadPostcovid_Diplomat.pdf Acesso em: 19 de Agosto de 2020.

TRIOLO \& GREENE 2020 - TRIOLO, Paul \& GREENE, Robert: A China controlará a Internet global por meio de sua Rota da Seda Digital? SupChina, 2020. Disponível em: https://supchina.com/2020/05/08/will-china-control-the-global-internet-via-its-digital-silk-road/ Acesso em: 12 de Setembro de 2020.

TREVISAN, Karina: Guerra Comercial: entenda as questões entre China e Eua e as incertezas para a economia mundial. G1, 2019. Disponível em: https://g1.globo.com/economia/noticia/2019/08/16/guerra-comercial-entenda-a-piora-dastensoes-entre-china-e-eua-e-as-incertezas-para-a-economiamundial.ghtml Acesso em: 5 de Setembro de 2020.

TYBRING-GJEDDE 2020: TYBRING-GJEDDE, Christian: China's Belt and Road Initiative: $A$ Strategic and Economic Assessment. NATO Parliamentary Assembly, 2020. Disponível em: 
https://www.nato-pa.int/document/2020-chinas-belt-and-road-initiative-strategic-andeconomic-assessment-033-esc-20-e Acesso em: 18 de Agosto de 2020.

THE WASHINGTON POST 2019: How Huawei became a target for governments. The Washington Post, 2019. Disponível em: https://www.washingtonpost.com/business/howhuawei-became-a-target-for-governments/2019/11/22/302af044-0d4f-11ea-8054 289aef6e38a3_story.html Acesso em: 3 de Setembro 2020.

TRIOLO, BROWN, ALLISON, BRODERICK 2020 - TRIOLO, Paul, BROWN, Clarise, ALLISON , Kevin, BRODERICK, Kelsey. Eurasia Group, 2020. Disponível em: https://www.eurasiagroup.net/live-post/digital-silk-road-expanding-china-digital-footprint Acesso em: 08 de Setembro de 2020

THE ECONOMIST 2020: Is it the end of the oil age? The Economist, 2020 Disponivel em: https://www.economist.com/leaders/2020/09/17/is-it-the-end-of-the-oilage?utm_campaign=the-economist-this-

week\&utm_medium=newsletter\&utm_source=salesforce-marketing-cloud Acesso em: 20 de Setembro de 2020.

VALOR INVESTE 2020: Trump diz que permitirá acordo se Walmart e Oracle tiverem controle total do Tik Tok. Valor Invest, 2020. Disponível em: https://valorinveste.globo.com/ Acesso em: 20 de Setembro de 2020.

XINHUA 2019: Jornal chinês tem escritor robô de notícias científicas. Xinhua, 2019. Disponível em: http://portuguese.xinhuanet.com/2019-08/02/c_138277869.htm Acesso em: 25 de Agosto de 2019

XINHUA 2020- China highlights cooperation on COVID-19 in Belt and Road projects. Xinhua, 2020. Disponível em: http://www.xinhuanet.com/english/2020-08/17/c_139297296.htm Acesso em:15 de Setembro de 2020.

XINHUA 2020 - Greece-China cooperation under BRI will progress despite covid-19 pandemic: oficials, experts. Xinhua, 2020. Disponível pelo link: http://www.xinhuanet.com/english/2020-05/30/c_139099374.htm Acesso em: 27 de Julho de 2020.

ZOU 2020: ZOU, Rene: Assessing the impact of covid-19 on the Belt and Road Initiative. China US Focus, 2020. Disponível em: https://www.chinausfocus.com/financeeconomy/assessing-the-impact-of-covid-19-on-the-belt-and-road-initiative Acesso em: 10 de Agosto de 2020.

WORLD ECONOMIC FORUM: How will covid-19 affect China's Belt and Road Initiative? World Economic Forum, 2020.2 Disponível em: https://www.weforum.org/agenda/2020/05/covid-19-coronavirus-disrupt-chinas-bri/ Acesso: 7 de Setembro de 2020.

WHEELER, Andre: China's Digital Silk Road (DSR): the new frontier in the Digital Arms Race? Silk Road Briefing, 2020.2 Disponível em: https://www.silkroadbriefing.com/news/2020/02/19/chinas-digital-silk-road-dsr-new-frontierdigital-arms-race/ Acesso em: 23 de Agosto de 2020. 


\section{NOTAS DE AUTOR}

\section{CONTRIBUIÇÃO DE AUTORIA}

Ana Carolina Pimenta Cordeiro - Investigação, concepção e análise de dados, e elaboração do manuscrito. Demian Castro - Revisão e aprovação da versão final do trabalho.

\section{FINANCIAMENTO}

Não se aplica.

\section{CONSENTIMENTO DE USO DE IMAGEM}

Não se aplica.

\section{APROVAÇÃO DE COMITÊ DE ÉTICA EM PESQUISA}

Não se aplica.

\section{LICENÇA DE USO}

Este artigo está licenciado sob a Licença Creative Commons CC-BY. Com essa licença você pode compartilhar, adaptar, criar para qualquer fim, desde que atribua a autoria da obra.

\section{HISTÓRICO}

Recebido em: 29-09-2020

Aprovado em: 14-10-2020 